\title{
A Fast Geometric Type2 Fuzzy Controller Using Barometric Sensor for Altitude Stabilization QuadRotor
}

\author{
Hendi Wicaksono $^{(1)}$, Yohanes Gunawan ${ }^{(2)}$, Cornellius Kristanto ${ }^{(3)}$ \\ Electrical Engineering Dept. \\ University of Surabaya \\ Indonesia \\ hendi@staff.ubaya.ac.id ${ }^{(1)}$, indetailhendi@gmail.com ${ }^{(1)}$, yohanesgunawan@staff.ubaya.ac.id ${ }^{(2)}$, cornelelektro@gmail.com ${ }^{(3)}$
}

\begin{abstract}
In this paper, a fast geometric Type2 Fuzzy developed for altitude stabilization with a barometric sensor as an input. MS5611-01BA03 as a barometric sensor to measure altitude of QuadRotor. The barometric sensor outputs are pressure value and temperature. This two kind of outputs should be converted to altitude value. An attitude which comes out from MS5611-01BA03 cannot be really steady like as a sonar sensor output to measure the altitude. This is the challenge in our research. With sonar sensor, it has produced a steady measurement, but it's having a limitation of height measurement below $300 \mathrm{~cm}$ only. In the other side, barometric sensor can measure any altitude, but an outputs have a random noise for one measurement in QuadRotor applications. As a data information to the controller, that random noise will be having a big effect if processed by simple controller, so the QuadRotor cannot steady in one of desired altitude. For that reason, this paper proposes the method to reducing the effect of random noise of MS5611-01BA03 outputs for altitude stabilization using a complex controller Type2 Fuzzy.
\end{abstract}

Keywords-Type2 Fuzzy controller; fast geometric defuzzification method; quadrotor altitude stabilization; barometric sensor MS5611-01BA03.

\section{INTRODUCTION}

Type2 Fuzzy or T2-Fuzzy developed from around twenty years ago. Comparing between Type2 Fuzzy with Type1 Fuzzy or ordinary Fuzzy, Type2 Fuzzy structure have the possibility to solve higher non-linear system than Type1 Fuzzy. This Type2 Fuzzy structure has ability to solve uncertainty and imprecision better than the other one. There are some publications on Type2 Fuzzy design, for example, Karnik and Mendel 1998 [1] present an "extended" defuzzification operation in Type1 Fuzzy to get an output crisp. Next publication is interval Type2 Fuzzy logic systems: theory and design by Mendel [2], this paper told us about the simplified method to compute beginning of input, antecedent operation from Type2 Fuzzy general form. Karnik and Mendel also in 2001 [3] present a centroid and generalized centroid of a Type 2 Fuzzy set and how to calculate them. Type 2 Fuzzy, very complex to make a real time. And in 2002, Mendel [4] present how make Type2 Fuzzy sets more simple without reduces a lot ability of Type2 Fuzzy. Researchers think harder to make this Type2 Fuzzy can be realized in portable because many applications cannot bring the computer with them. So, in this publication, an approach to Type2 Fuzzy arithmetic [5] show us some approach to make Type2 Fuzzy actual to be realized in portable controller. But, Coupland in [6] told that Type2 Fuzzy with arithmetic loss many features of Type2 Fuzzy causes the ability to handle uncertainty and imprecision reduced. Coupland proposed new method called fast geometric defuzzification replace general type reducer which Mendel said. This method proved that features of Type2 Fuzzy not loss so many than other methods, but still can realized well using portable controller. In [7] Type2 Fuzzy use fast geometric defuzzification realized for biomedical application. This publication shows that method can realized for real time application.

In the above, around first ten years Type2 Fuzzy developed still research about mathematic model of Type2 Fuzzy. Starting at 2004, some higher non-linear plant uses Type2 Fuzzy as a controller. For example in 2004, Type2 Fuzzy applied in mobile robot application [8] using the interval Type2 Fuzzy method. In 2007, Biped robot application uses Type2 Fuzzy for its movement [9]. In Type2 Fuzzy as a controller for manipulator [10] also use interval Type2 Fuzzy. Also in [11], Widodo use interval Type2 Fuzzy in obstacle avoidance robot. Almost all real time applications above use interval Type2 Fuzzy method.

One of higher non-linear systems is QuadRotor system. The main problem in QuadRotor plant is a robust controller designed with the ability to solve non-linear system of QuadRotor. With three dimensional movements also many disturbance sources on QuadRotor system make this system have a higher non-linear level. Type2 Fuzzy controller fit as a controller for QuadRotor applications. In the last decade, QuadRotor system developed in many topic research. That research can divided into 2 categories development of QuadRotor. First, a mathematic model development usually uses an Ar.Drone like was developed in [12]. Second, hardware or QuadRotor real applications development for an example is attitude stabilization research [13]. In our research, we develop altitude lock based on barometric sensor with Type2 Fuzzy first than develop Type1 Fuzzy caused by a random noise coincide with barometric sensor output.

The body of the paper is organized as follows. Section Two describes QuadRotor and YoHe Board Design. Type2 Fuzzy 
theory and design are given in Section Three and Section Four. The Section Five describes the experimental results, and finally in the last section, a summary of this research given.

\section{QUAdRotor AND YoHe BoARD DESIGN}

QuadRotor used in this research build from Whirlwind FY450 frame, KK2.0 board as a flight controller will produce a variation pulse to control motor with a same angular speed based on its IMU sensors, ZTW Spider 30A Electronic Speed Controller (ESC), NTM Prop Drive $1000 \mathrm{KV}$ brushless motor, and Dji 10x4.7 propeller. Our QuadRotor and its parts shown in Fig. 1.

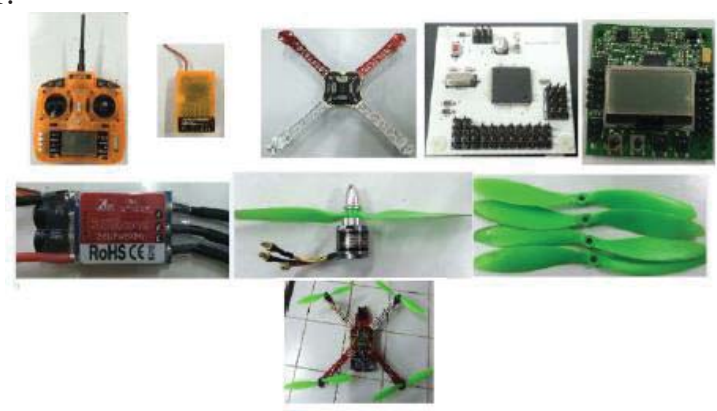

Fig. 1. QuadRotor and Parts

The Type2 Fuzzy processed on-board which attached on QuadRotor. YoHe board designed for that purpose. YoHe board powered with ATMega 2560 microcontroller. ATMega 2560 with $256 \mathrm{~KB}$ ROM Program Memory clearly enough for building a Type2 Fuzzy with Fast Geometric Defuzzification. YoHe board has a compact dimension about $12 \mathrm{~cm}^{2}$ so the board will be fit in the frame correctly. There is a special connection between KK2.0 board, YoHe board, ESC, and barometric sensor. The connection between all of them can see in Fig. 2.

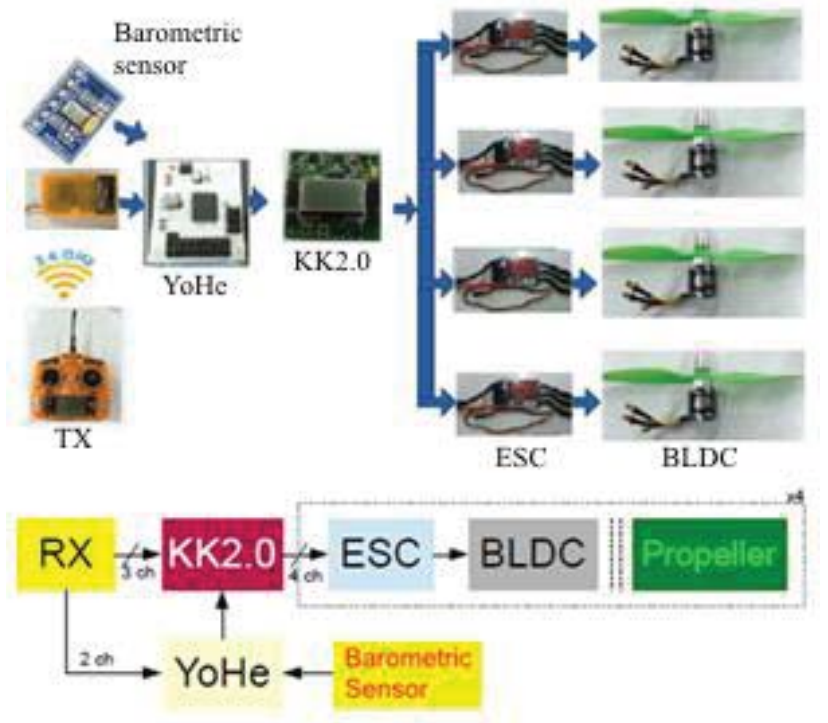

Fig. 2. The Connection of KK2.0, YoHe, ESC, and Barometric Sensor

The Control process of Altitude Stabilization QuadRotor with Barometric Sensor using Type2 Fuzzy shown in Fig. 3. Type2 Fuzzy have two inputs and one output. A two inputs are error and delta error value, and the output is throttle value. Error value be obtained from difference desired height and actual height or height (n), while delta error is the difference between error now error (n) and error (n-1). The actual height is the result measurement from barometric sensor. Theory and design of Type2 Fuzzy will be explained in next section.

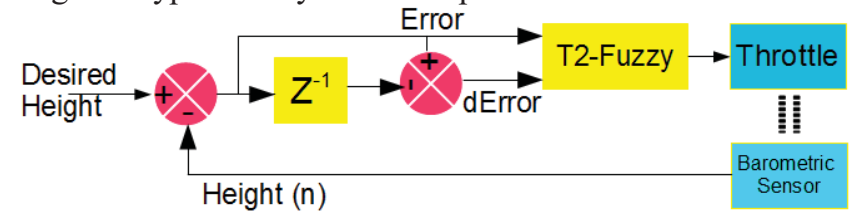

Fig. 3. Altitude Stabilization using Type2 Fuzzy Control Process

\section{FAST GEOMETRIC TYPE2 FUZZY THEORY}

Major difference between Type1 Fuzzy and Type2 Fuzzy is Type1 Fuzzy only one dimensional, while Type2 Fuzzy in two dimensions. A crisp input $\mathrm{x}$ has a membership function $\mu(\mathrm{x})$. That is like Typel Fuzzy. Continuing to the next level, we consider $\mu(\mathrm{x})$ is $\mathrm{u}$ then the level two is $\mu(\mathrm{x}, \mathrm{u})$. More clearly about that description in Fig. 4. Each crisp input $\mathrm{x}$ will have membership function $\mu(\mathrm{x})$ where $0 \leq \mu(\mathrm{x}) \leq 1$ and also have secondary membership function $\mu(\mathrm{x}, \mathrm{u})$ where $0 \leq \mu(\mathrm{x}, \mathrm{u}) \leq 1$.

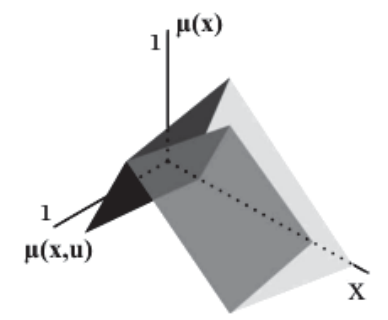

Fig. 4. Type2 Fuzzy Sets $x$ with Triangular Model

The next step is inference and rule examination. In this step neither difference between both of Fuzzy. However, in defuzzification step, there are two process in this step. They are type reduction will be reduced to Type1 Fuzzy number, after that it can be defuzzified to give a crisp output. That processes cannot do in general form because the complexity calculation. A Fast Geometric Defuzzification is a method of defuzzification without type reduction first, but used geometric approximation. A result of inference, assume it's produce a fuzzy set positive small. We should divide that fuzzy sets into a number of discrete points in $\mathrm{x}$-axis for $\mathrm{x}$ points and $\mathrm{y}$-axis for $\mu(\mathrm{x})$ points, also $\mathrm{z}-$ axis for $\mu(\mathrm{x}, \mathrm{u})$ shown in Fig. 5. We can see that both axis divided into 6 points. From that figure build a triangle to connect each points, so it will be constructing a polyhedron form. The main process in the Fast Geometric method is transforming that polyhedron fuzzy sets into 5 areas, area a, area b, area c, area d, and area e. The position about that 5 areas shown in Fig. 6.

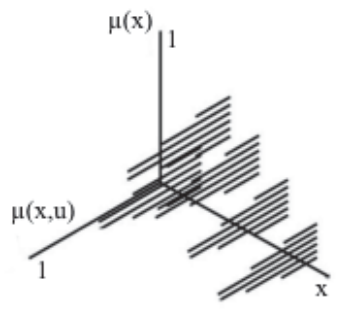

Fig. 5. Fuzzy Sets Divided into 6 Points 


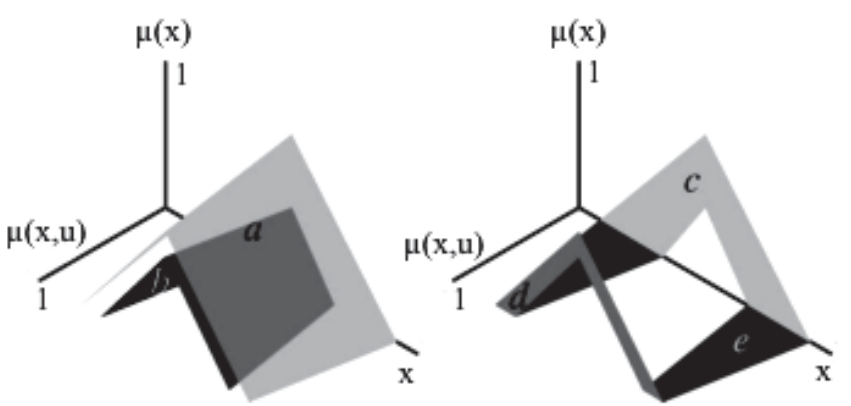

Fig. 6. Five Surface Areas

A groups of triangle coordinate for each area build use (1) (10). This formula very helped when we created an array of them in programming.

$$
\begin{aligned}
& a=a \cup\left\{\left[\begin{array}{ccc}
x_{i} & u_{i, j} & \mu\left(x_{i}, u_{i, j}\right) \\
x_{i} & u_{i, j+1} & \mu\left(x_{i}, u_{i, j+1}\right) \\
x_{i+1} & u_{i+1, j+1} & \mu\left(x_{i+1}, u_{i+1, j+1}\right)
\end{array}\right]\right\} \\
& a=a \cup\left\{\left[\begin{array}{ccc}
x_{i} & u_{i, j} & \mu\left(x_{i}, u_{i, j}\right) \\
x_{i+1} & u_{i+1, j+1} & \mu\left(x_{i+1}, u_{i+1, j+1}\right) \\
x_{i+1} & u_{i+1, j} & \mu\left(x_{i+1}, u_{i+1, j}\right)
\end{array}\right]\right\} \\
& b=b \cup\left\{\left[\begin{array}{ccc}
x_{i} & u_{i, j} & \mu\left(x_{i}, u_{i, j}\right) \\
x_{i+1} & u_{i+1, j+1} & \mu\left(x_{i+1}, u_{i+1, j+1}\right) \\
x_{i} & u_{i, j+1} & \mu\left(x_{i}, u_{i, j+1}\right)
\end{array}\right]\right\} \\
& b=b \cup\left\{\left[\begin{array}{ccc}
x_{i} & u_{i, j} & \mu\left(x_{i}, u_{i, j}\right) \\
x_{i+1} & u_{i+1, j} & \mu\left(x_{i+1}, u_{i+1, j}\right) \\
x_{i+1} & u_{i+1, j+1} & \mu\left(x_{i+1}, u_{i+1, j+1}\right)
\end{array}\right]\right\} \\
& c=c \cup\left\{\left[\begin{array}{ccc}
x_{i} & u_{i, 1} & 0 \\
x_{i+1} & u_{i+1, n} & 0 \\
x_{i} & u_{i n} & 0
\end{array}\right]\right\} \\
& c=c \cup\left\{\left[\begin{array}{ccc}
x_{i} & u_{i, 1} & 0 \\
x_{i+1} & u_{i+1,1} & 0 \\
x_{i+1} & u_{i+1, n} & 0
\end{array}\right]\right\} \\
& d=d \cup\left\{\left[\begin{array}{ccc}
x_{i} & u_{i, \alpha(i)} & 1 \\
x_{i+1} & u_{i+1, \beta(i+1)} & 1 \\
x_{i} & u_{i, \beta(i)} & 1
\end{array}\right]\right\} \\
& d=d \cup\left\{\left[\begin{array}{ccc}
x_{i} & u_{i, \alpha(i)} & 1 \\
x_{i+1} & u_{i+1, \alpha(i+1)} & 1 \\
x_{i+1} & u_{i+1, \beta(i+1)} & 1
\end{array}\right]\right\} \\
& e=e \cup\left\{\left[\begin{array}{ccc}
x_{i} & 0 & 0 \\
x_{i} & 0 & u_{i, 1} \\
x_{i+1} & 0 & u_{i+1,1}
\end{array}\right]\right\} \\
& e=e \cup\left\{\left[\begin{array}{ccc}
x_{i} & 0 & 0 \\
x_{i+1} & 0 & u_{i+1,1} \\
x_{i+1} & 0 & 0
\end{array}\right]\right\}
\end{aligned}
$$

The form of one triangle will be formatted like (11). From that triangle, we find out $\mathrm{C}$ for every triangle. $\mathrm{C}$ is centroid every triangle (12). We also find out the area of triangle (13).

$$
\begin{gathered}
t^{i}=\left[\begin{array}{lll}
x_{1}^{i} & y_{1}^{i} & z_{1}^{i} \\
x_{2}^{i} & y_{2}^{i} & z_{2}^{i} \\
x_{3}^{i} & y_{3}^{i} & z_{3}^{i}
\end{array}\right] \\
C^{i}=\frac{x_{1}^{i}+x_{2}^{i}+x_{3}^{i}}{3} \\
A^{i}=0.5 \sqrt{\begin{array}{l}
\left(\left(y_{2}^{i}-y_{1}^{i}\right)\left(z_{3}^{i}-z_{1}^{i}\right)-\left(y_{3}^{i}-y_{1}^{i}\right)\left(z_{2}^{i}-z_{1}^{i}\right)\right)^{2} \\
+\left(\left(x_{2}^{i}-x_{1}^{i}\right)\left(z_{3}^{i}-z_{1}^{i}\right)-\left(x_{3}^{i}-x_{1}^{i}\right)\left(z_{2}^{i}-z_{1}^{i}\right)\right)^{2} \\
+\left(\left(x_{2}^{i}-x_{1}^{i}\right)\left(y_{3}^{i}-y_{1}^{i}\right)-\left(x_{3}^{i}-x_{1}^{i}\right)\left(y_{2}^{i}-y_{1}^{i}\right)\right)^{2}
\end{array}}
\end{gathered}
$$
(14).

The centroid of geometric Type2 Fuzzy for every area is

$$
C=\frac{\sum_{i=1}^{n} C^{i} A^{i}}{\sum_{i=1}^{n} A^{i}}
$$

If we make a short summary about the process are after we get all the points every triangle in each area from the area a until area e, next we should calculate centroid $\left(\mathrm{C}^{\mathrm{i}}\right)$ and area $\left(\mathrm{A}^{\mathrm{i}}\right)$ of triangles. Continuing calculate centroid of geometric $(\mathrm{C})$ area a until area e, the final is we find out centroid of area like a Type1 Fuzzy as a crisp output using (15).

$$
C o A=\frac{C A_{a}+C A_{b}+C A_{c}+C A_{d}+C A_{e}}{\sum A_{a}+\sum A_{b}+\sum A_{c}+\sum A_{d}+\sum A_{e}}
$$

\section{TYPE2 FUZZY DESIGN}

The first step before we can define the values of the Input Membership Function (IMF) and also an Output Membership Function (OMF), we tried to flee QuadRotor with remote control. We tried to make stabilize in one height which we knew it is very hard to do. We analyze behavior of QuadRotor focusing on the values of throttle, error. For optimization all parameters, we did step by step, firstly from rule evaluation, secondly optimize IMF starting from Upper Membership Function (UMF) continue to Lower Membership Function (LMF). Third, we optimize OMF starts with UMF first and continue to LMF of OMF. The rules table evaluation drawing can see in Fig. 7.

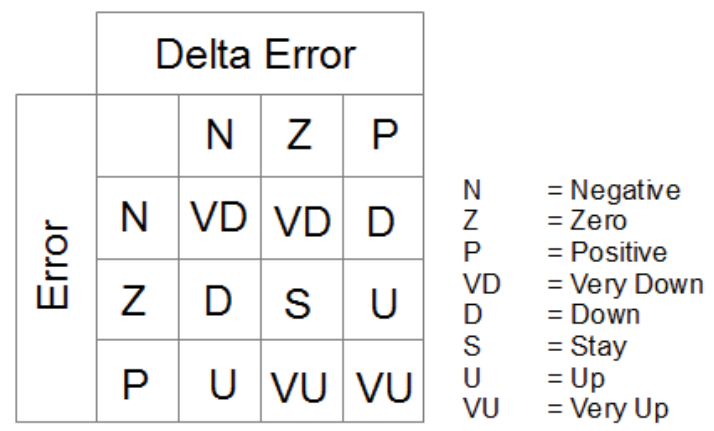

Fig. 7. Rules Table 


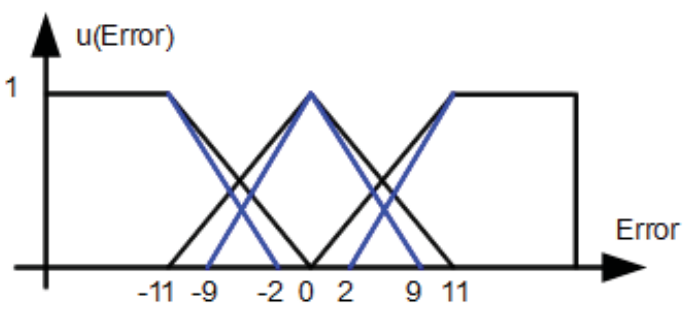

Fig. 8. IMF Error

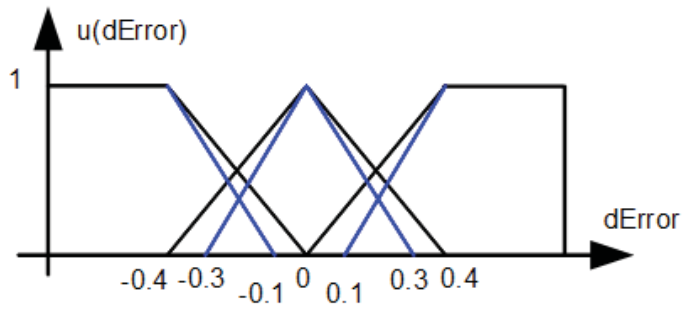

Fig. 9. IMF dError

After trial and error, tried repeatedly to change the parameter, make is fleeing in $150 \mathrm{~cm}$ height, record the data, compare each other, and the best one of IMF parameter shown at Fig. 8 and Fig. 9. The QuadRotor flight always in outdoor environment with a slow wind speed. Meanwhile, did it the same way to get an optimal OMF, and OMF parameter shown at Fig. 10. And in Fig. 11 and Fig. 12, we can see all history changing parameters to get as shown as Fig. 8, Fig. 9, and Fig. 10.

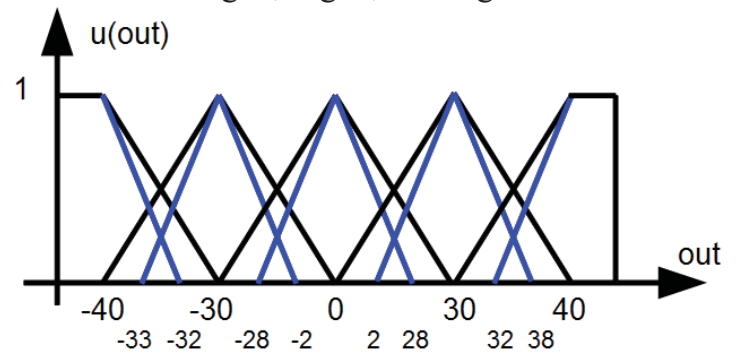

Fig. 10. OMF

During IMF optimization, parameter of OMF be letting all fixed, a height stabilization can reach. Next, after getting the best setting value for IMF, continue to OMF optimization.

\section{EXPERIMENTS AND RESULTS}

The experiments using QuadRotor which was descripted in Section 2. QuadRotor flight in outdoor an early morning to get slow speed of wind around $6.00 \mathrm{am}-10.00 \mathrm{am}$. We use the Bluetooth V3 to get a data, focusing on throttle values and height values. The QuadRotor will transfer that both of data to the laptop so that it is possible to analyze the flight data. For every experiment take about only 5 minutes because for make sure that the battery still has enough power. The results of combining the best parameter of IMF and OMF tested in four desired height, $250 \mathrm{~cm}, 300 \mathrm{~cm}, 350 \mathrm{~cm}$, and $400 \mathrm{~cm}$. The purpose of this testing is to find out that Type2 Fuzzy parameter was obtained to all height desired though when parameter optimizing use trial and error in $150 \mathrm{~cm}$ height only. Four results shown at Fig. 13. The black line is as a desired height in $\mathrm{cm}$, the blue line is as a MA-30 in $\mathrm{cm}$, and the red line is as a height measurement also in $\mathrm{cm}$ with the $\mathrm{x}$-axis is a sample data from 1 to 400 data, and for the $y$-axis is a $\mathrm{cm}$. In that figure, we can see in height measurements still appear vary values around one height measurement caused by a random noise of a barometric sensor output. We applied moving average 30 (MA30) for measured an oscillation. The minimum oscillation occurred when desired height is $400 \mathrm{~cm}$ and the maximum occurred when height is $350 \mathrm{~cm}$.

\begin{tabular}{|c|}
\hline $\begin{array}{l}\text { MIF }(3,3) \\
\text { error UMIF : }-5(1), 0(0) ;-5(0), 0(1), 5(0) ; 0(0), 5(1) \\
\text { error LMF : }-5(1),-2(0) ;-3(0), 0(1), 3(0) ; 2(0), 5(1) \\
\text { derror UMF : ... } \\
\text { derror LMF : ... }\end{array}$ \\
\hline 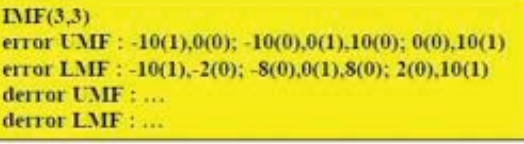 \\
\hline $\begin{array}{l}\text { MIF }(3,3) \\
\text { error LMF : }-15(1), 0(0) ;-15(0), 0(1), 15(0) ; 0(0), 15(1) \\
\text { error LIF :-15(1),-2(0);-13(0),0(1),13(0);2(0),15(1) } \\
\text { derror UMF : ... } \\
\text { derror LMF : ... }\end{array}$ \\
\hline 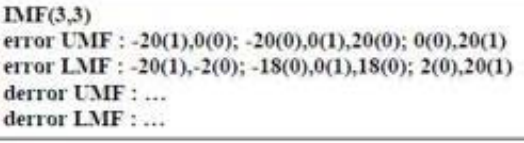 \\
\hline $\begin{array}{l}\text { MIF (3,3) } \\
\text { error UMF : }-25(1), 0(0) ;-25(0), 0(1), 25(0) ; 0(0), 25(1) \\
\text { error LIF : -25(1),-2(0);-23(0),0(1),23(0);2(0),25(1) } \\
\text { derror UMF : ... } \\
\text { derror LMF : ... }\end{array}$ \\
\hline
\end{tabular}

Fig. 11. IMF (UMF + LMF) Optimization Step by Step

\begin{tabular}{|c|}
\hline $\begin{array}{l}\text { IMF }(3,3) \\
\text { error UMF : }-5(1), 0(0) ;-5(0), 0(1), 5(0) ; 0(0), 5(1) \\
\text { error L.IF : }-5(1),-2(0) ;-3(0), 0(1), 3(0) ; 2(0), 5(1) \\
\text { derror UMF : } \ldots \\
\text { derror LMF : ... }\end{array}$ \\
\hline 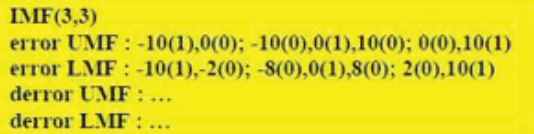 \\
\hline $\begin{array}{l}\text { IMIF }(3,3) \\
\text { error UMF : }-15(1), 0(0) ;-15(0), 0(1), 15(0) ; 0(0), 15(1) \\
\text { error LMIF : }-15(1),-2(0) ;-13(0), 0(1), 13(0) ; 2(0), 15(1) \\
\text { derror UMIF : } \ldots \\
\text { derror LMIF : .. }\end{array}$ \\
\hline $\begin{array}{l}\text { IMF }(3,3) \\
\text { error UMF : - 20(1),0(0);-20(0),0(1),20(0);0(0),20(1) } \\
\text { error LMF : -20(1),-2(0);-18(0),0(1),18(0);2(0),20(1) } \\
\text { derror UMF : ... } \\
\text { derror LMIF : ... }\end{array}$ \\
\hline $\begin{array}{l}\text { IMF }(3,3) \\
\text { error UMF : }-25(1), 0(0) ;-25(0), 0(1), 25(0) ; 0(0), 25(1) \\
\text { error LMF : }-25(1),-2(0) ;-23(0), 0(1), 23(0) ; 2(0), 25(1) \\
\text { derror UMF : } \ldots \\
\text { derror LMF : } \ldots\end{array}$ \\
\hline
\end{tabular}

Fig. 12. OMF (UMF + LMF) Optimization Step by Step 


\section{CONCLUSION}

In this paper, we presented Type2 Fuzzy with a fast geometric defuzzification method and its novel application to QuadRotor in real application in dynamic unstructured outdoor environment. To the author's knowledge, this is the first paper that applying Type2 Fuzzy in real time QuadRotor control and real time processing with YoHe Board.

This paper has shown how Type2 Fuzzy can handle uncertainty higher non-linearity found in the QuadRotor system and make a good response due to a random noise at barometric sensor. Type 2 Fuzzy produce a good real time responses about $39 \mathrm{~cm}-60 \mathrm{~cm}$ oscillation used barometric sensor.

\section{REFERENCES}

[1] N. Karnik and J. Mendel, "Type2 fuzzy logic systems: Type reduction," Syst. Man, Cybern. 1998.

[2] J. M. Mendel, "Interval Type2 fuzzy logic systems: theory and design," IEEE Trans. Fuzzy Syst., vol. 8, no. 5, pp. 535-550, 2000.

[3] N. N. Karnik and J. M. Mendel, "Centroid of a Type2 fuzzy set," Inf. Sci. (Ny)., vol. 132, no. 1-4, pp. 195-220, Feb. 2001.

[4] J. R. Mendel JM, “Type2 Fuzzy Sets Made Simple,” IEEE Trans. Fuzzy Syst., vol. 10(2), pp. 117-127, 2002.

[5] S. Coupland and R. John, "An approach to Type2 fuzzy arithmetic," 2003.

[6] S. Coupland and R. John, "A Fast Geometric Method for Defuzzification of Type2 Fuzzy Sets," IEEE Trans Fuzzy Syst., vol. 16, no. 4, pp. 929-941, 2008.

[7] H. Wicaksono, "Fast Geometric T2-Fuzzy Based Improved Lower Extremities Stimulation Response," Telkomnika, pp. 207-216, 2010.

[8] H. Hagras, "A Type2 fuzzy logic controller for autonomous mobile robots," 2004 IEEE Int. Conf. Fuzzy Syst. (IEEE Cat. No.04CH37542), vol. 2, pp. 965-970, 2004.

[9] Z. Liu, Y. Zhang, and Y. Wang, "A Type2 Fuzzy Switching Control System for Biped Robots," IEEE Trans. Syst. Man Cybern. Part C (Applications Rev., vol. 37, no. 6, pp. 1202-1213, Nov. 2007.

[10] H. Chaoui and W. Gueaieb, "Type2 Fuzzy Logic Control of a Flexible-Joint Manipulator," Intell Robot Syst, pp. 159-186, 2008.

[11] W. Budiharto, B. Kanigoro, and C. Nugraheni, "Obstacles Avoidance for Intelligent Telepresence Robot Using Interval Type2 FLC," ICIC Int., vol. 8, no. 3, pp. 1-7, 2014.

[12] J. Faigl and T. Krajnık, "Surveillance planning with localization uncertainty for UAVs," 3rd Isr. Conf. ..., 2010.

[13] I. González, S. Salazar, J. Torres, R. Lozano, and H. Romero, "Real-Time Attitude Stabilization of a MiniUAV Quad-rotor Using Motor Speed Feedback," J. Intell. Robot. Syst., vol. 70, no. 1-4, pp. 93-106, Aug. 2013.

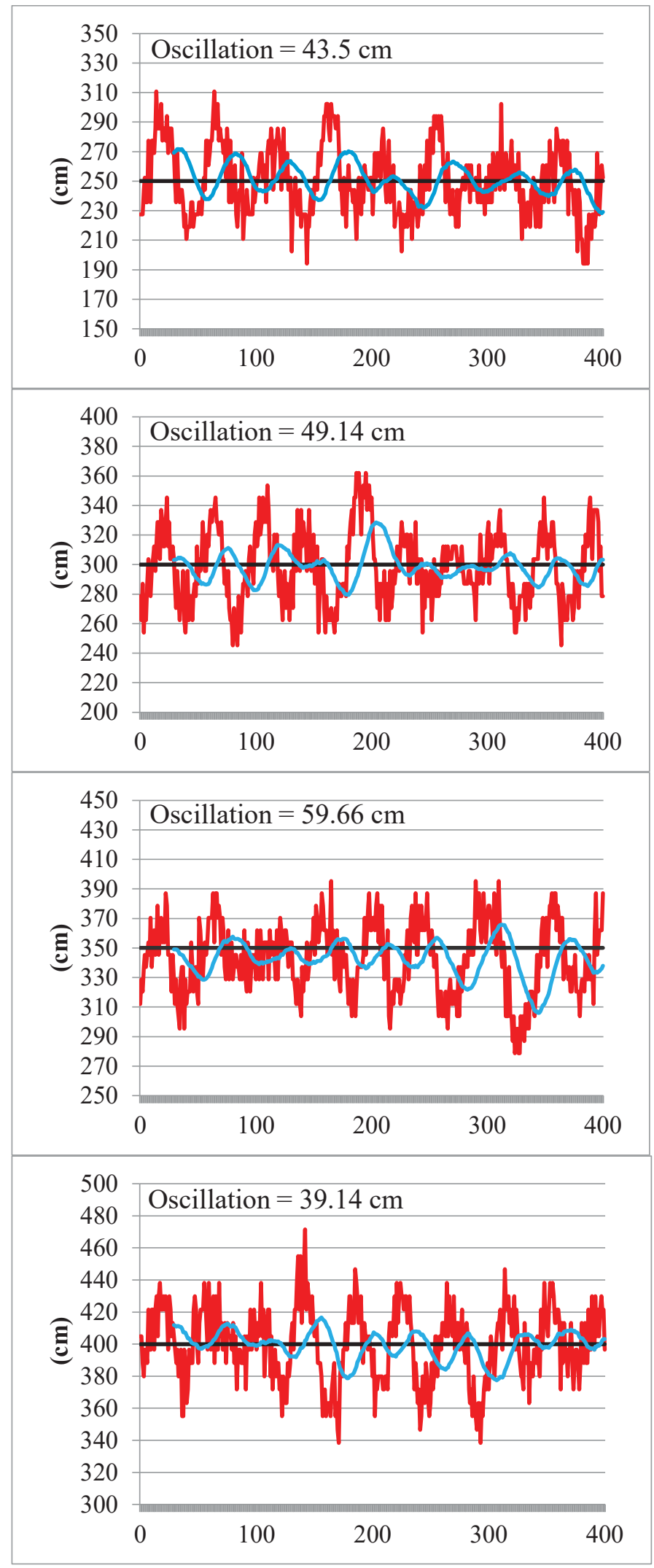

Fig. 13. Variance Desired Height from $250 \mathrm{~cm}, 300 \mathrm{~cm}, 350 \mathrm{~cm}, 400 \mathrm{~cm}$ 


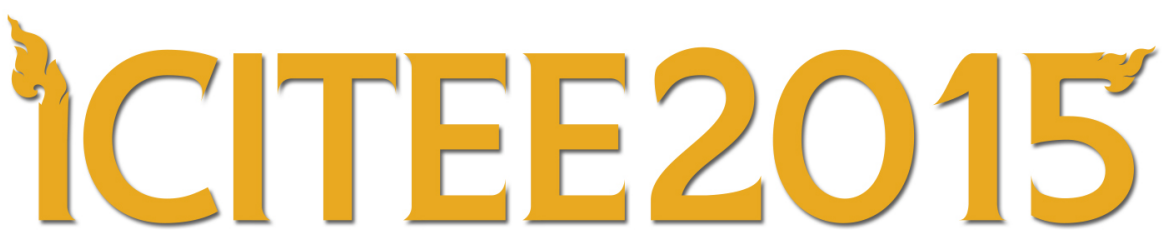

2015 The $7^{\text {th }}$ International Conference on Information Technology and Electrical Engineering

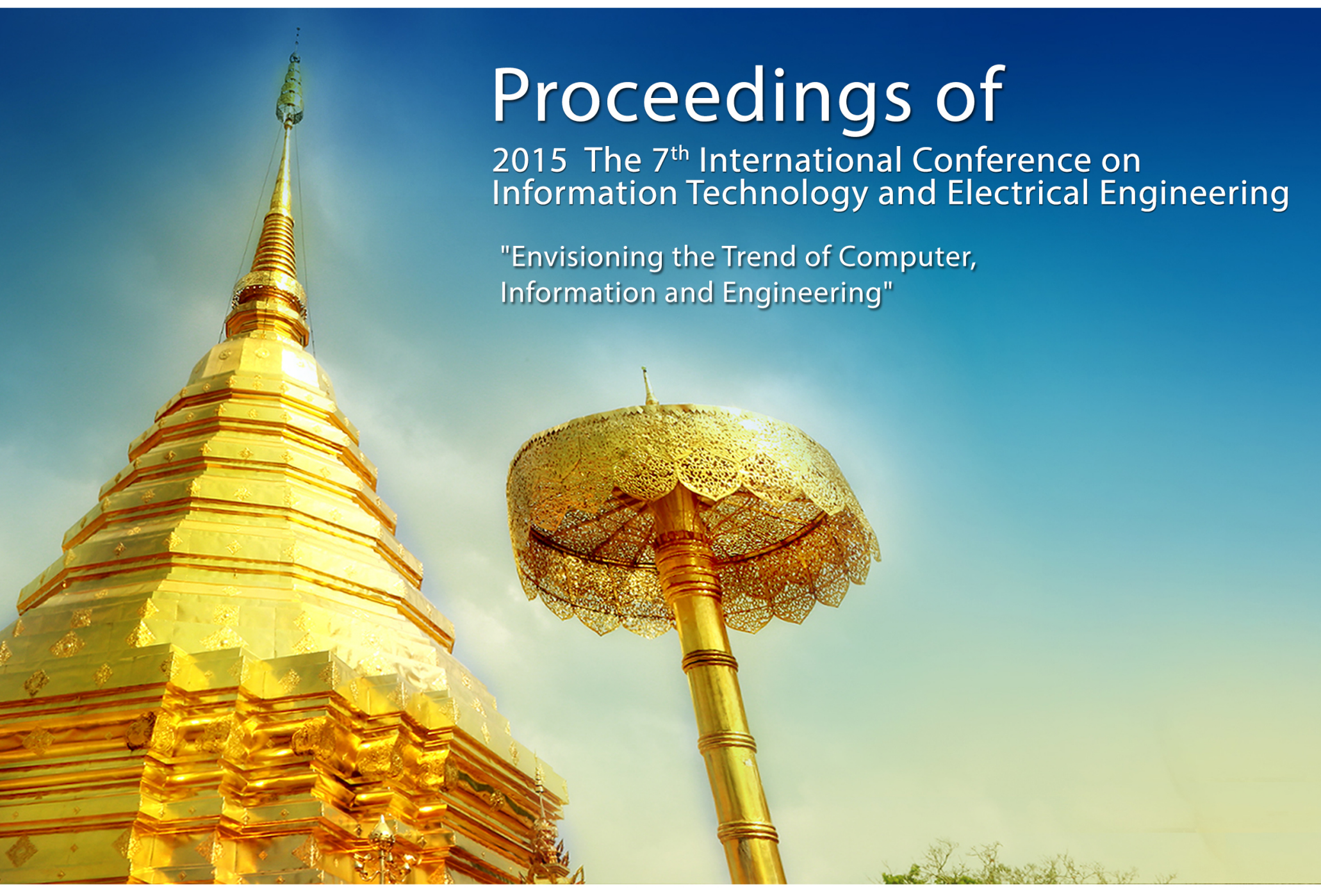

Le Méridien Chiang Mai Hotel, Thailand 29-30 October 2015

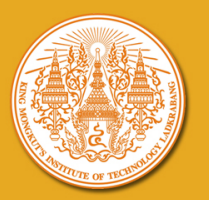

Organized by

Faculty of Information Technology

King Mongkut's Institute of Technology Ladkrabang, THAILAND 


\section{Proceedings - 2015 7th International Conference on Information Technology and Electrical Engineering: Envisioning the Trend of Computer, Information and Engineering, ICITEE 2015}

COUNTRY

United States

Universities and research institutions in United States

PUBLICATION TYPE

Conferences and Proceedings
SUBJECT AREA AND CATEGORY

Computer Science

Artificial Intelligence

Computer Science Applications

Information Systems

Engineering

Electrical and Electronic Engineering

Scopus Indexed Jour

Call for Papers August Issue

Fast Track Peer Reviewed Public:

tojqinet

OPEN
PUBLISHER H-INDEX

10

COVERAGE

2015 


\section{Scopus Indexed Journ:}

Call for Papers August Issue

Fast Track Peer Reviewed Publicatio

tojqi.net

OPEN

Join the conversation about this journal

Azelique, Serumdipity, Age Refining Collagen, Facial Serum, $1 \mathrm{fl} \mathrm{oz} \mathrm{(30} \mathrm{ml)}$

Build \& Hydratelmproves Moisture Content of SkinHydrolyzed Marine CollagenSmooths \& Plumps SkinReduces Appearance of Fine Lines \& WrinklesQuick AbsorbingpH BalancedSuitable for All Skin Types ${ }^{\star}$ Eco-Friendly PackagingCruelty Free 
SJR

no data

2015

External Cites per Doc

Cites per Doc

ネ围

NB

0

NB

2015

$\%$ International Collaboration

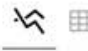

NB

8.8

NB

2015

Cited documents Uncited documents

๙

NB

NB

2015

\section{G SClmago Graphica}

Explore, visually communicate and make sense of data with our new free tool.

Get it

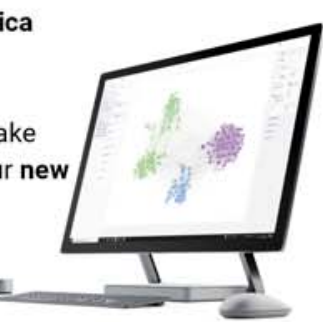

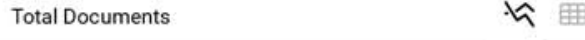

NB

125

NB

2015

Citations per document
NB

2015

Cites / Doc. (4 years)

- Cites / Doc. (3 years)

- Cites / Doc. (2 years)

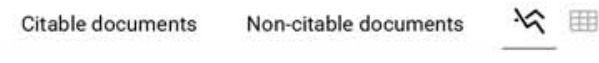

NB

2015

\begin{tabular}{|c|c|}
\hline $\begin{array}{l}\text { Proceedings }-20157 \text { th } \\
\text { International Conference on }\end{array}$ & $\begin{array}{l}\leftarrow \text { Show this widget in } \\
\text { your own website }\end{array}$ \\
\hline $\begin{array}{l}\text { Not yet assigned } \\
\text { quartile }\end{array}$ & $\begin{array}{l}\text { Just copy the code below } \\
\text { and paste within your html } \\
\text { code: }\end{array}$ \\
\hline $\begin{array}{r}\text { SJR } 2020 \\
0\end{array}$ & henf-"bthane \\
\hline & $<a$ href="https://www.scim \\
\hline
\end{tabular}

powered by scimagoir com 
Azelique, Serumdipity, Age Refining Collagen, Facial Serum, $1 \mathrm{fl} \mathrm{oz} \mathrm{(30} \mathrm{ml)}$

Build \& Hydratelmproves Moisture Content of SkinHydrolyzed Marin CollagenSmooths \& Plumps SkinReduces Appearance of Fine Lines \& WrinklesQuick AbsorbingpH BalancedSuitable for All Skin Types`Eco-Friendly Packaging Cruelty Free

\section{Leave a comment}

Name

Email

(will not be published)

The users of Scimago Journal \& Country Rank have the possibility to dialogue through comments linked to a specific journal. The purpose is to have a forum in which general doubts about the processes of publication in the journal, experiences and other issues derived from the publication of papers are resolved. For topics on particular articles, maintain the dialogue through the usual channels with your editor. 


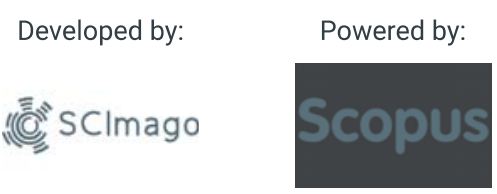

Follow us on @ScimagoJR

Scimago Lab, Copyright 2007-2020. Data Source: Scopus ${ }^{\circledR}$ 


\section{Proceedings}

\section{7th International Conference on \\ Information Technology and Electrical Engineering}

"Envisioning the Trend of Computer, Information and Engineering"

29-30 October 2015

Le Méridien Chiang Mai Hotel

Chiang Mai, Thailand 


\section{COPYRIGHTS}

\section{7th International Conference on Information Technology and Electrical Engineering (ICITEE)}

Copyright (C2015 by Institute of Electrical and Electronics Engineers, Inc. All rights reserved.

\section{Copyright and Reprint Permission:}

Abstracting is permitted with credit to the source. Libraries are permitted to photocopy beyond the limit of U.S. copyright law for private use of patrons those articles in this volume that carry a code at the bottom of the first page, provided the per-copy fee indicated in the code is paid through Copyright Clearance Center, 222 Rosewood Drive, Danvers, MA 01923.

For other copying, reprint, or reproduction requests should be emailed to IEEE Copyrights Manager at pubs-permissions@ieee.org. All rights reserved. Copyright (C2015 by IEEE.

IEEE Catalog Number : CFP15TEF-ART

ISBN

: 978-1-4673-7863-5 


\title{
2015 7th International Conference on Information Technology and Electrical Engineering (ICITEE)
}

\author{
Software Engineering, Services, and Information Technology
}

\begin{abstract}
A Means for Visualization of Skills in Software Development Takahiro Yonamine (National Institute of Technology, Sendai Hirose Campus, Japan), Takeichi Yoshihiro (National Institute of Technology Tsuruoka College, Japan), Yajima Kuniaki (Information Networks System \& National Institute of Technology Sendai College, Japan), Jun Sato (National Institute of Technology Tsuruoka College, Japan), Makoto Yamazaki (Nagaoka National College of Technology, Japan), Yasushi Kato (Tsuruoka National College of Technology, Japan)

Bytecode-based Class Dependency Extraction Tool: Bytecode-CDET

Aziz Nanthaamornphong (Prince of Songkla University, Phuket campus, Thailand), Anwat Leatongkam (Prince of Songkla University, Phuket campus, Thailand), Thanyarat Kitpanich (Prince of Songkla University, Phuket campus, Thailand), Pongsakorn Thongnuan (Prince of Songkla University, Phuket campus, Thailand)

Factors of Influence in Software Process Improvement: An ISO/IEC 29110 for Very-Small Entities

Noppachai Wongsai (Prince of Songkla University, Phuket Campus, Thailand), Veeraporn Siddoo (Prince of Songkla University, Phuket Campus, Thailand), Rattana Wetprasit (Prince of Songkla University, Phuket Campus, Thailand) 12

Requirements Traceability on Web Applications

Waraporn Jirapanthong (Dhurakij Pundit University, Thailand) 18

A Software System Family Learning From Simple Data Processing to Knowledge

Management System of Research

Inggriani Liem (Institut Teknologi Bandung, Indonesia), Transmissia

Semiawan (Politeknik Negeri Bandung, Indonesia), Suprihanto Suprihanto

(Bandung State Polytechnic, Indonesia), Ade Chandra Nugraha (Bandung

State of Polytechnic, Indonesia)

\section{Software Engineering, Services, and Information Technology}

A Hybrid Genetic Algorithm with Local Search and Tabu Search Approaches for Solving the Post Enrolment Based Course Timetabling Problem: Outperforming Guided Search Genetic Algorithm

Dome Lohpetch (King Mongkut's University of Technology North Bangoko

(KMUTNB), Thailand), Sawaphat Jaengchuea (KMUTNB, Thailand)

A Comparative Study of Optimization Methods for Improving Artificial Neural Network Performance

Jesada Kajornrit (Dhurakij Pundit University, Thailand) 35

A Hybrid Ensemble of Machine and Statistical Learning Using Confidence-Based Boosting

Nattawut Chairatanasongporn (King Mongkut's Institute of Technology

Ladkrabang, Thailand), Saichon Jaiyen (King Mongkut's Institute of

Technology Ladkrabang, Thailand) 
SEMG Signal Classification Using SMO Algorithm and Singular Value
Decomposition

Yotsapat Ruangpaisarn (King Mongkut's Institute of Technology Ladkrabang, Thailand), Saichon Jaiyen (King Mongkut's Institute of Technology

Ladkrabang, Thailand) 46

A Hybrid Differential Evolution with Grey Wolf Optimizer for Continuous Global Optimization

Duangjai Jitkongchuen (Dhurakij Pundit University, Thailand) 51

\section{Software Engineering, Services, and Information Technology}

Negative Content Filtering for Video Application

Hanung Adi Nugroho (Universitas Gadjah Mada, Indonesia), Denny Hardiyanto (Universitas Gadjah Mada, Indonesia), Teguh Bharata Adji (Universitas Gadjah Mada, Indonesia)

Robust Multi-directional Bicycle Recognition on the Rotation Using the In-vehicle

Cameras

Kenta Fukushima (National Institute of Technology, Kurume College, Japan), Kousuke Matsushima (National Institute of Technology, Kurume College, Japan)

Research and Development of the Social Robot Using Speech Recognition and Image Sensing Technology

Yukiko Miura (National Institute of Technology, Kitakyushu College, Japan), Shigeru Kuchii (National Institute of Technology, Kitakyushu College, Japan), Chung Sern Goh (Nanyang Polytechnic, Singapore), He Yihao (Nanyang

Polytechnic, Singapore)

A Rapid Motion Retrieval Technique Using Simple and Discrete Representation of Motion Data

Natapon Pantuwong (King Mongkut's Institute of Technology Ladkrabang, Thailand), Kensuke Takahara (Hokkaido University, Japan), Masanori

Sugimoto (Hokkaido University, Japan) 70

The Development of Image-based Algorithm to Identify Altitude Change of a Quadcopter

Nemuel Daniel Pah (Universitas Surabaya, Indonesia), Henry Hermawan

(Universitas Surabaya, Indonesia)

\section{Wireless Communications, Networking, and Vehicular Technology}

Development of Hybrid VANET Routing Protocol Between Buses and Cars

Phongsathorn Boonnithiphat (Faculty of Engineering, Chiang Mai University, Thailand), Yuthapong Somchit (Faculty of Engineering, Chiang Mai University, Thailand)

Compact Dual Wideband Asymmetric Cross Patch Antenna Fed by Cross Strip Line for WLAN and WiMAX Applications

Yuktitath Chawanonphithak (Rajamangala University of Technology Isan, Thailand) 
Feasible Solution of Power Control in the Presence of Primary User in Cognitive Radio Networks

I Wayan Mustika (Universitas Gadjah Mada, Indonesia), Norma Amalia (UGM, Indonesia), Selo Sulistyo (Gadjah Mada University, Indonesia)

A Detection Technique for High Order QAM in the Presence of Transmitter Angular Skew

Sawitree Wongroekdee (Khon Kaen University, Thailand, Thailand), Puripong Suthisopapan (Rajamangala University of Technology Isan Khon Kaen, Thailand, Thailand), Virasit Imtawil (Khon Kaen University, Thailand, Thailand)

Reversible Cyclic Codes Over F4 + u F4 and Their Applications to DNA Codes

Srinivasulu B (Indian Institute of Technology Roorkee, India), Maheshanand Bhaintwal (Indian Institute of Technology Roorkee, India)

\title{
Electronics, Circuits, and Systems
}

\author{
Single VDGA-Based First-Order Allpass Filter with Electronically Controllable \\ Passband Gain \\ Jetsdaporn Satansup (Rajamangala University of Technology Rattanakosin, \\ Thailand), Worapong Tangsrirat (King Mongkut's Institute of Technology
} Ladkrabang, Thailand)

Simple Design Technique for Realizing Low-Voltage Low-Power CMOS Current

Multiplier

Jetwara Tangjit (King Mongkut's Institute of Technology Ladkrabang, Thailand), Jetsdaporn Satansup (Rajamangala University of Technology Rattanakosin, Thailand), Worapong Tangsrirat (King Mongkut's Institute of Technology Ladkrabang, Thailand), Wanlop Surakampontorn (National

Science Technology and Innovation Policy Office (STI), Thailand) 110

VDBA-based Floating Inductance Simulator with a Grounded Capacitor

Orapin Channumsin (Rajamangala University of Technology Isan, KhonKaen Campus, Thailand), Jirapun Pimpol (Suranaree University of Technology, Thailand), Chanchai Thongsopa (Suranaree University of Technology, Thailand), Worapong Tangsrirat (King Mongkut's Institute of Technology Ladkrabang, Thailand)

Sinusoidal Quadrature Oscillator Using Voltage Differencing Gain Amplifiers (VDGAs)

Orapin Channumsin (Rajamangala University of Technology Isan, KhonKaen Campus, Thailand), Worapong Tangsrirat (King Mongkut's Institute of Technology Ladkrabang, Thailand)

Single VDCC-based Current-mode Universal Biquadratic Filter

Panit Lamun (King Mongkut's Institute of Technology Ladkrabang Prince of Chumphon Campus, Thailand), Punnavich Phatsornsiri (Pathumwan Institute of Technology, Thailand), Usa Torteanchai (Civil Aviation Training Center, Thailand) 


\section{Software Engineering, Services, and Information Technology}

Querying Ontology Through HTTP Protocol to Bridge Interoperability and Platform Difference

Sri Suning Kusumawardani (Universitas Gadjah Mada, Indonesia), Robertus Sonny Prakoso (Universitas Gadjah Mada, Indonesia), Paulus Santosa

(Universitas Gadjah Mada, Indonesia) 126

Design of Speech-based Thai Information Retrieval System in Desktop Device for Blind People

Jantima Polpinij (Faculty of Informatics, Mahasarakham University, Thailand), Thongparn Suksamer (Faculty of Informatics, Mahasarakham University, Mahasarakham, Thailand)

A Refugee Tracking System in dCoST-ER: Disaster Command and Support Centre for Emergency Response

Lukito Edi Nugroho (Universitas Gadjah Mada, Indonesia), Kurnianingsih Kurnianingsih (Universitas Gadjah Mada \& Politeknik Negeri Semarang, Indonesia), Arkham Rakhman (Universitas Gadjah Mada, Indonesia), Widy Widyawan (Universitas Gadjah Mada, Indonesia), Lutfan Lazuardi (Universitas Gadjah Mada, Indonesia)

Proposed Framework for Automatic Entity Relationship Diagram Grading System

Humasak Simanjuntak (Institut Teknologi Del, Indonesia) 141

Jaccard Coefficent-based Word Sense Disambiguration Using Hybrid Knowledge Resource

Su Mu Tyar (Yangon Technological University, Myanmar), Thanda Win (Yangon Technological University, Myanmar)

\section{Control Systems}

Development of Sequence Control Learning Kit for the PBL

Toshiki Takayama (Sendai National Institute of Technology, Japan), Sugaya Junichi (National Institute of Technology Sendai College, Japan), Okumura Toshiaki (National Institute of Technology Sendai College, Japan), Yajima Kuniaki (Information Networks System \& National Institute of Technology Sendai College, Japan)

The Development of Fundamental Teaching Materials and the Inverted Pendulum

System as Advanced Sequence Control

Sugaya Junichi (National Institute of Technology Sendai College, Japan), Iishiba Yuuta (Advanced Course of Electronic System Engineering, Japan), Yajima Kuniaki (Information Networks System \& National Institute of Technology Sendai College, Japan)

Development of Sequence Control Kit and A Proposal of Global Engineering PBL Education

Yajima Kuniaki (Information Networks System \& National Institute of Technology Sendai College, Japan), Okumura Toshiaki (National Institute of Technology Sendai College, Japan), Sugaya Junichi (National Institute of Technology Sendai College, Japan), Takeichi Yoshihiro (National Institute of Technology Tsuruoka College, Japan), Jun Sato (National Institute of Technology Tsuruoka College, Japan) 
Model-Based Stator Interturn Short-circuit Fault Detection and Diagnosis in Induction Motors

Sssr Sarathbabu, DUVVURI (IIT Hyderabad, India), Ketan Detroja (Indian

Institute of Technology Hyderabad, India)

Robust Fine-Tuned PID Controller Using Taguchi Method for Regulating DC Motor

Speed

Gunawan Dewantoro (Satya Wacana Christian University, Indonesia)

\section{Power Systems}

Review of Research on Measurement Technologies of DC High Voltage

Yu Zhang (Huazhong University of Science and Technology, P.R. China), Xia

Xiao (Huazhong University of Science and Technology, P.R. China), Xu Yan

(Huazhong University of Science and Technology, P.R. China)

Investigation of Copper Sulphide Effect on Paper Impregnated Oil

Hendar Prisnadianta (ITB \& PLN, Indonesia), Dr Suwarno (Institut Teknologi

Bandung, Indonesia), Andrea Cavallini (University of Bologna, Italy), Gian

Carlo Montanari (University of Bologna, Italy)

Design of a Wireless Current Monitoring System for Distribution Feeders

Siriluk Satthasujarit (King Mongkut's University of Technology North Bangkok, Thailand), Noppadol Charbkaew (King Mongkut's University of Technology North Bangkok, Thailand), Teratam Bunyagul (King Mongkut's University of Technology North Bangkok, Thailand)

Five Level Single Phase Inverter Scheme with Fault Tolerance for Islanded Photovoltaic Applications

Siva Kumar K (Indian Institute of Technology Hyderabad, India), Madhukar A (IIT Hyderabad, India)

Quadratic Programming Approach for Security Constrained Optimal Power Flow

Rony Seto Wibowo (Institut Teknologi Sepuluh Nopember, Indonesia), Rendhi Maulana (Sepuluh Nopember Institute of Technology, Indonesia), Annisaa Taradini (Institute Teknologi Sepuluh Nopember, Indonesia), Feby Agung Pamuji (Institute Teknologi Sepuluh Nopember, Indonesia), Adi Soeprijanto (Institut Teknologi Sepuluh Nopember, Indonesia), Ontoseno Penangsang

(Institut Teknologi Sepuluh Nopember, Indonesia) 200

Impact Analysis of Fast Charging to Voltage Profile in PEA Distribution System by Monte Carlo Simulation

Sanchai Dechanupaprittha (Kasetsart University, Thailand)

\section{Software Engineering, Services, and Information Technology}

\section{Analysis of Auto-Fluorescence Images for Automatic Detection of Abnormalities} in Oral Cavity

Muhammad Awais (Universiti Teknologi PETRONAS, Malaysia), Nicolas Walter (Universiti Teknologi PETRONAS \& Centre for Intelligent Signal and Imaging Research (CISIR), Malaysia), Ibrahima Faye (UTP, Malaysia) 
A Novel Algorithm for Detection Human Falling From Accelerometer Signal Using Wavelet Transform and Neural Network

Nitipat Nuttaitanakul (King Mongkut's Institute of Technology Ladkrabang, Thailand), Thurdsak Leauhatong (Electronics and Telecommunication

Engineering, Thailand) 215

Modified Differential Box-Counting Method Using Weighted Triangle-Box Partition

Walairach Nunsong (King Mongkut's Institute of Technology Ladkrabang, Thailand), Kuntpong Woraratpanya (KMITL, Thailand)

Image Layout and Camera-Human Positioning Scheme for Communicative

Collaboration

Thitiporn Lertrusdachakul (Thai-Nichi Institute of Technology, Thailand)

Distance Measurement Using 3D Stereoscopic Technique for Robot Eyes

Sainatee Boonkwang (Khon Kean University \& Faculty of Science, Thailand),

Saiyan Saiyod (Khon Kaen University, Thailand)

Particle-Flow Interactive Animation for Painting Image

Nutchaphon Rewik (King Mongkut's Institute of Technology Ladkrabang, Thailand), Kittipop Peuwnuan (King Mongkut's Institute of Technology Ladkrabang, Thailand), Kuntpong Woraratpanya (King Mongkut's Institute of Technology Ladkrabang, Thailand), Kitsuchart Pasupa (King Mongkut's Institute of Technology Ladkrabang, Thailand)

\section{Software Engineering, Services, and Information Technology}

A Simple Saturation-based Image Fusion Technique for Static Scenes

Geley Peljor (Sirindhorn International Institute of Technology, Thammasat University, Thailand), Toshiaki Kondo (Sirindhorn International Institute of Technology, Thammasat University, Thailand)

Robust Implementation of Hand Gesture Recognition for Remote Human-

Machine Interaction

Jakkrit Dulayatrakul (Sirindhorn International Institute of Technology \& Thammasat University, Thailand), Pawin Prasertsakul (Sirindhorn International Institute of Technology, Thammasat University, Thailand), Itthisek Nilkhamhang (Sirindhorn International Institute of Technolgy, Thammasat University, Thailand), Toshiaki Kondo (Sirindhorn International Institute of Technology, Thailand)

Automatic Hemorrhages Detection Based on Fundus Images

Syna Sreng (King Mongkut's Institute of Technology Ladkrabang, Thailand), Noppadol Maneerat (King Mongkut's Institute of Technology Ladkrabang, Thailand), Don Isarakorn (King Mongkut's Institute of Technology Ladkrabang, Thailand), Kazuhiko Hamamoto (Tokai University, Japan), Ronakorn Panjaphongse (Ophthalology Department, Bhumibol Adulyadej Hospital, Thailand) 253

Offline Handwritten Signature Recognition Using Adaptive Variance Reduction

Ruangroj Sa-Ardship (KMITL, Thailand), Kuntpong Woraratpanya (KMITL, Thailand) 258

Rain Removal From Still Images Using LO Gradient Minimization Technique

Manu BN (Independent Researcher, India) 263 
Automatic Batik Motifs Classification Using Various Combinations of SIFT Features Moments and k-Nearest Neighbor

Iwan Setyawan (Satya Wacana Christian University, Indonesia), Ivanna Timotius (Satya Wacana Christian University, Indonesia), Marchellius Kalvin (Satya Wacana Christian University, Indonesia) 269

\section{Wireless Communications, Networking, and Vehicular Technology}

Virtual Machine Placement Method for Energy Saving in Cloud Computing Pragan Wattanasomboon (Faculty of Engineering, Chaing Mai University, Thailand), Yuthapong Somchit (Faculty of Engineering, Chiang Mai University, Thailand)

Usage Time Limiting Technique for Supporting a Large Number of Users in Wi-Fi Network

Suchada Chomjan (Kasetsart University, Thailand), Aphirak Jansang (Kasetsart University, Thailand), Anan Phonphoem (Kasetsart University, Thailand)

An Improvement of Video Streaming Service Using Dynamic Routing Over Openflow Network

Sutheera Puntheeranurak (Faculty of Engineering, King Mongkut's Institute of Technology Ladkrabang, Thailand), Nipith Sa-ngarmangkang (Ramkhamhaeng University, Thailand)

The Analysis of Drainage Paths in Chao Phraya River Basin by Graph Theory

Nitinan Mata (King Mongkut's University of Technology North Bangkok, Thailand), Panida Lorwongtrakool (Rajamangala University of Technology Isan \& Mueng, Nakhonratchasima, Thailand), Sangdaow Noppitak (Buriram Rajabhat University, Thailand), Sirorat Kulwong (Buriram Rajabhat University, Thailand)

An Efficient Message Flooding Scheme in Delay-Tolerant Networks

Worrawat Narongkhachavana (King Mongkut's Institute of Technology Ladkrabang, Thailand), Teerapong Choksatid (King Mongkut's Institute of Technology Ladkrabang, Thailand), Sumet Prabhavat (King Mongkut's Institute of Technology Ladkrabang, Thailand)

An Efficient Flow Table Replacement Algorithm for SDNs with Heterogeneous

Switches

Dongryeol Kim (University of Kyonggi, Korea), Dongjoo Choi (Kyonggi

University, Korea), Namgi Kim (Kyonggi University, Korea), Byoung-Dai Lee

(Kyonggi University, Korea) 300

\section{Electronics, Circuits, and Systems}

High Frequency Rectifier for RF Energy Harvesting Systems

Ekkaphol Khansalee (Chulalongkorn University, Thailand), Yan Zhao

(Chulalongkorn University, Thailand), Kittipong Nuanyai (Phetchaburi

Rajabhat University, Thailand) 304

Application of a Two-Phase Interleaved Step-Up Converter for Photovoltaic Power Maximization

Adirek Buakam (Naresuan University, Thailand), Niphat Jantharamin (Naresuan University, Thailand) 
Front-End Interfacing Circuit for Capacitive Sensor

Akira Ota (Faculty of Engineering, King Mongkut's Institute of Technology Ladkrabang, Thailand), Wandee Petchmaneelumka (Faculty of Engineering, King Mongkut's Institute of Technology Ladkrabang, Thailand), Thepjit Cheypoca (Faculty of Engineering, King Mongkut's Institute of Technology Ladkrabang, Thailand), Apinai Rerkratn (Faculty of Engineering, King Mongkut's Institute of Technology Ladkrabang, Thailand), Vanchai Riewruja (Faculty of Engineering, King Mongkut's Institute of Technology Ladkrabang, Thailand)

A Real-Time Khim Sound Synthesizer Using IIR Resonator Implemented with A DSP Board

Chukiet Sodsri (Silpakorn University, Thailand), Rattasat Yutipong (Silpakorn

University, Thailand), Tirawat Boonrat (Silpakorn University, Thailand)

An Internet-based Coaxial Switching System for an Amateur Radio Station with

Multiple Antennas

Watchara Amasiri (Thammasat University, Thailand), Saran Lerdnantawat

(Thammasat University, Thailand), Dahmmaet Bunnjaweht (Thammasat

University, Thailand)

Design of Time Reduction for Successive Approximation Register A/D Converter

Mon Mon Thin (YTU, Myanmar), Myo Min Than (YTU, Myanmar)

\section{Wireless Communications, Networking, and Vehicular Technology}

Comparison of RDBMS and Document Oriented Database in Audit Log Analysis

Chanankorn Jandaeng (Walailak University, Thailand) 332

The Mobile Technologies Performance Comparison for Internet Services in Bangkok

Suttisak Jantavongso (Rangsit University, Thailand), Sanon Chimmanee

(Rangsit University, Thailand), Sittisak Kantala (Rangsit University, Thailand)

Stackelberg Bargaining-Based Allocation for Multi-Source Relay Networks

Wei Heng (Southeast University, P.R. China), Tian Liang (Southeast

University, P.R. China), Fang Long (Southeast University, P.R. China), Jinming Hu (Southeast University, P.R. China), Chao Meng (Jinling Institute of Technology \& School of Networks and Telecommunications Engineering, P.R.

China)

A Context-Awareness Approach for Improving Reporting Protocol for Activity and

Position Tracking for Social Networking Services

Waskitho Wibisono (Institut Teknologi Sepuluh Nopember, Indonesia),

Annisaa Indrawanty (Institut Teknologi Sepuluh Nopember, Indonesia),

Tohari Ahmad (Institut Teknologi Sepuluh Nopember (ITS), Indonesia) 348

Intrusion Detection Model Based on Ensemble Learning for U2R and R2L Attacks

Ployphan Sornsuwit (King Mongkut's Institute of Technology Ladkrabang, Thailand), Saichon Jaiyen (King Mongkut's Institute of Technology

Ladkrabang, Thailand) 


\title{
Control Systems
}

\author{
Comparison of Two Fuzzy Logic Controller Schemes for Position Control of \\ AR.Drone \\ Veronica Indrawati (University of Surabaya, Indonesia), Agung Prayitno \\ (University of Surabaya \& Indonesia, Indonesia), Gabriel Utomo (University of \\ Surabaya, Indonesia) \\ 360 \\ Indirect Vector Control of Induction Motors Using a PI-Fuzzy Controller with the \\ Simplified Implementation Without Current Sensors \\ Itthiphan Sakunwanthanasak (KMITL, Thailand), Siridech Boonsang (KMTIL, \\ Thailand) \\ 364 \\ Object Identification Using Knocking Sound Processing and Reaction Force From \\ Disturbance Observer \\ Watcharada Hamontree (Kasetsart University, Thailand), Chowarit Mitsantisuk \\ (Kasetsart University, Thailand), Jantanee Rungrangpitayagon (Kasetsart \\ University, Thailand) \\ WayBot: a Low Cost Manipulator for Playing Javanesee Puppet \\ Sisdarmanto Adinandra (Universitas Islam Indonesia, Indonesia), Nugroho \\ Adhilaga (Universitas Islam Indonesia, Indonesia), Dani Erfawan (Universitas \\ Islam Indonesia, Indonesia) \\ 376 \\ Design and Implementation of an AUV for Petroleum Pipeline Inspection \\ 'Yodyium Tipsuwan (Kasetsart University, Thailand) \\ 382 \\ Spraying Analysis for a Coconut Climbing Robot \\ Navapan Suparat (KMUTT, Thailand) \\ 388
}

\section{Power Systems}

High Voltage Test on 245 kV Post Insulators with Different Materials Made Gita Mardika (Bandung Institute of Technology \& PT. PLN (Persero), Indonesia), Tri Andhika Puri (Bandung Institute of Technology \& PT. PLN (Persero), Indonesia), Michael Walch (Graz University of Technology, Austria), Uwe Schichler (Graz University of Technology, Austria), Gustav Goedel (PPC Insulators $\mathrm{GmbH}$, Austria), Suwarno Suwarno (Institut Teknologi Bandung, P.R. China)

\section{Software Engineering, Services, and Information Technology}

\section{Analysis of the Internet Using Behavior of Adolescents by Using Data Mining} Technique

Chonnikarn Rodmorn (BTU, Thailand), Mathuros Panmuang (BTU, Thailand), Khuanwara Potiwara (BTU, Thailand) 398

Improving Key Concept Extraction Using Word Association Measurement

Phuoc Doan (Khon Kaen University, Thailand), Ngamnij Arch-in (Khonkaen University, Thailand), Somjit Arch-Int (Khon Kaen University, Thailand) 
A Proposed Method for Personal Attributes Disclosure Valuation: A Study on Personal Attributes Disclosure in Thailand

Ake Osothongs (SOKENDAI(The Graduate University for Advanced Studies) \& National Institute of Informatics, Japan), Vorapong Suppakitpaisarn (The University of Tokyo \& JST, ERATO, Kawarabayashi Large Graph Project, Japan), Noboru Sonehara (National Institute of Infomatics, Japan)

Finding Potential Influencers of a Specific Financial Market in Twitter

Nont Kanungsukkasem (King's Mongkut Institute of Technology Ladkrabang, Thailand), Teerapong Leelanupab (King Mongkut's Institute of Technology Ladkrabang, Thailand)

A Comparison of Feature Selection Approach Between Greedy, IG-ratio, Chisquare, and $m R M R$ in Educational Mining

Nachirat Rachburee (Faculty of Engineering, Rajamangala University of Technology Thanyaburi, Thailand), Wattana Punlumjeak (Faculty of Engineering, Rajamangala University of Technology Thanyaburi, Thailand)

A Comparative Study of Feature Selection Techniques for Classify Student Performance

Wattana Punlumjeak (Faculty of Engineering, Rajamangala University of Technology Thanyaburi, Thailand), Nachirat Rachburee (Faculty of Engineering, Rajamangala University of Technology Thanyaburi, Thailand)

\section{Software Engineering, Services, and Information Technology}

Tracking-Based Human Entry/Exit Detection on Various Video Resolutions ( $A$ Study on Parameter Effects)

Wongsatorn Saelao (King Mongkut's Institute of Technology Ladkrabang, Thailand), Somkiat Wangsiripitak (King Mongkut's Institute of Technology Ladkrabang, Thailand), Wirat Rattanapitak (King Mongkut's Institute of Technology Ladkrabang, Thailand) 430

Segmentation of Exudates Based on High Pass Filtering in Retinal Fundus Images

Hanung Adi Nugroho (Universitas Gadjah Mada, Indonesia), KZ Widhia Oktoeberza (Universitas Gadjah Mada, Indonesia), Teguh Bharata Adji (Universitas Gadjah Mada, Indonesia), Muhammad Bayu Sasongko (Universitas Gadjah Mada, Indonesia)

Segmentation of Skin Cancer Images Using an Extension of Chan and Vese Model

Faouzi Adjed (Universiti Teknologi PETRONAS \& Université d'Evry Val d'Essonne France, Malaysia), Ibrahima Faye (Universiti Teknologi PETRONAS, Malaysia), Fakhreddine Ababsa (University of Evry, France)

An Improved 2DPCA for Face Recognition Under Illumination Effects

Kuntpong Woraratpanya (KMITL, Thailand), Monmorakot Sornnoi (King

Mongkut's Institute of Technology Ladkrabang, Thailand), Savita Leelaburanapong (King Mongkut's Institute of Technology Ladkrabang, Thailand), Taravichet Titijaroonroj (King Mongkut's Institute of Technology Ladkrabang, Thailand), Ruttikorn Varakulsiripunth (Thai-Nichi Institute of Technology, Thailand), Yoshimitsu Kuroki (National Institute of Technology, Kurume College, Japan), Yasushi Kato (National Institute of Technology, Tsuruoka College, Japan) 448

The Multi Vehicle Recognition Using Hybrid Blob Analysis and Feature-Based

Anchisa Chantakamo (King Mongkut's University of Technology North Bangkok, Thailand), Mahasak Ketcham (King Mongkut's University of Technology North Bangkok, Thailand) 
Zernike Moment Feature Extraction for Classifying Lesion's Shape of Breast Ultrasound Images

Hanung Adi Nugroho (Universitas Gadjah Mada, Indonesia), Hesti Khuzaimah Nurul Yusufiyah (Universitas Gadjah Mada, Indonesia), Teguh Bharata Adji (Universitas Gadjah Mada, Indonesia), Anan Nugroho (Universitas Gadjah

Mada, Indonesia)

\title{
Wireless Communications, Networking, and Vehicular Technology
}

\author{
Predicting Path Quality with Cross-layer Information in Multi-hop Wireless \\ Networks \\ Lapas Pradittasnee (King Mongkut's Institute of Technology Ladkrabang, \\ Thailand)
}

Energy-efficient Adaptive Lighting Control Scheme Using Indoor Localization with

Prior Position Information

Keita Nakashima (Nagoya Institute of Technology, Japan), Eiji Okamoto

(Nagoya Institute of Technology, Japan)

A Low-Cost Flash Flood Monitoring System

Ouychai Intharasombat (Nakhon Pathom Rajabhat University, Thailand)

Indoor Localization System Using Visible Light Communication

Panarat Cherntanomwong (King Mongkut's Institute of Technology

Ladkrabang, Thailand), Wisarut Chantharasena (King Mongkut's Institute of

Technology Ladkrabang, Thailand)

Pilot-Aided Double-Dwell Frequency Synchronization in OFDM Systems

Nour Kousa (American University of Sharjah, UAE), Mohamed El-Tarhuni

(American University of Sharjah, UAE)

The Repeater System for Visible Light Communication

Panarat Cherntanomwong (King Mongkut's Institute of Technology

Ladkrabang, Thailand), Pornchanok Namonta (King Mongkut's Institute of

Technology Ladkrabang, Thailand)

\section{Electronics, Circuits, and Systems}

Delay Design-for-Testability for Functional RTL Circuits

Ateeq-Ur-Rehman Shaheen (Universiti Teknologi PETRONAS, Malaysia), Fawnizu Azmadi Hussin (Universiti Teknologi Petronas, Malaysia), Nor Hisham Hamid (Universiti Teknologi Petronas, Malaysia)

Mixed-mode Quadrature Oscillator Using a Single DDCCTA and Grounded Passive

Components

Panit Lamun (King Mongkut's Institute of Technology Ladkrabang Prince of Chumphon Campus, Thailand), Punnavich Phatsornsiri (Pathumwan Institute of Technology, Thailand), Montree Kumngern (King Mongkut's Institute of Technology Ladkrabang, Thailand) 500

A Hybrid OTA-C Notch Filter for Physiological Signal Acquisition

Surachoke Thanapitak (Mahidol University, Thailand), Chutham Sawigun

(Mahanakorn University of Technology \& Centre for Bioelectronics Integrated Systems, Thailand) 
An On-Chip Delay Measurement Using Adjacency Testable Scan Design

Kentaro Kato (National Institute of Technology, Tsuruoka College, Japan), Somsak Choomchuay (King Mongkut's Institute of Technology Ladkrabang, BKK, Thailand) 508

Acceleration of Scan-Based On-Chip Delay Measurement Using Extra Latches and

Multiple Asynchronous Transfer Scan Chains

Kentaro Kato (National Institute of Technology, Tsuruoka College, Japan), Somsak Choomchuay (King Mongkut's Institute of Technology Ladkrabang, BKK, Thailand)

A Fast Geometric Type2 Fuzzy Controller Using Barometric Sensor for Altitude Stabilization QuadRotor

Hendi Wicaksono (University of Surabaya, Indonesia), Yohanes Gunawan (University of Surabaya, Indonesia), Cornelius Kristanto (University of Surabaya, Indonesia)

\section{Wireless Communications, Networking, and Vehicular Technology}

Maximum Likelihood Estimator of SNR for QAM Signals in AWGN Channel Nida Ishtiaq (NUST College of E\&ME, Pakistan), Shahzad Sheikh (NUST College of E\&ME, Pakistan)

Development of Circular Ring Antenna for Mobile Broadband Systems

Peuv Poch (Rajamangala University of Technology Thanyaburi, Thailand), Paitoon Rakluea (Rajamangala University of Technology Thanyaburi, Thailand) 530

Step Track Algorithm Using in Free Space Optics

Nuttapon Nakarach (King Mongkut's Institute of Technology Ladkrabang, Thailand), Panarat Cherntanomwong (King Mongkut's Institute of Technology Ladkrabang, Thailand)

Feasible Solution of Centralized Power Control for Multi Channel Cognitive Femtocell Network

Anggun Fitrian Isnawati (Gadjah Mada University (UGM) \& Telkom's Telematics School of Engineering (ST3 Telkom), Indonesia), Risanuri Hidayat (Gadjah Mada University (UGM), Indonesia), Selo Sulistyo (Gadjah Mada University, Indonesia), I Wayan Mustika (Universitas Gadjah Mada, Indonesia) 539

Study on CPW-Antenna for Wideband Coverage Mobile 4G/WLAN/WiMAX/UWB

Ornlarp Sangaroon (Faculty of Engineering, King Mongkut's Institute of Technology Ladkrabang \& Faculty of Engineering, Thailand), Noppin Anantrasirichai (King Mongkuts Institute of Technology Ladkrabang, Thailand), Paitoon Rakluea (Rajamangala University of Technology Thanyaburi, Thailand), Chawalit Rakluea (Rajamangala University of Technology Thanyaburi, Thailand), Peuv Poch (Rajamangala University of Technology Thanyaburi, Thailand) 


\section{Control Systems}

Model-Based Control for Tracking and Rejection of Periodic Signals

Edi Kurniawan (Indonesian Institute of Sciences, Indonesia), Riyo Wardoyo (Indonesian Institute of Sciences, Indonesia), Inna Syafarina (Indonesian Institute of Sciences, Indonesia)

Gain Scheduled Control for Active Magnetic Bearing System Considering Gyroscopic Effect

Akio Sanbayashi (Nanzan University, Japan), Masanori Narita (Nanzan University, Japan), Gan Chen (Nanzan University, Japan), Isao Takami (Nanzan University, Japan)

Robust Control of Control Moment Gyroscope with Friction Disturbance -Using

Polytopic Representation-

Toru Inaba (Nanzan University, Japan), Chinatsu Murai (Nanzan University, Japan), Gan Chen (Nanzan University, Japan), Isao Takami (Nanzan

University, Japan)

\section{Software Engineering, Services, and Information Technology}

Reducing Battery Consumption of Data Polling and Pushing Techniques on Android Using GZip

Sirapat Boonkrong (King Mongkut's University of Technology North Bangkok \& Faculty of Information Technology, Thailand), Pham Dinh (King Mongkut's

University of Technology North Bangkok, Thailand)

Multi-Thread Performance on a Single Thread In-Memory Database

Ramot Lubis (Binus University, Indonesia), Albert Sagala (Del Institute of Technology, Indonesia)

Automatic Snort IDS Rule Generation Based on Honeypot Log

Albert Sagala (Del Institute of Technology, Indonesia)

A System to Analyze Twitter Data for Social Science Study

Piyawat Lertvittayakumjorn (Chulalongkorn University, Thailand), Panida

Nimnual (Chulalongkorn University, Thailand), Peerapon Vateekul

(Chulalongkorn University, Thailand), Pijitra Tsukamoto (Chulalongkorn

University, Thailand)

\section{Software Engineering, Services, and Information Technology}

Framework for e-Learning Recommendation Based on Index of Learning Styles Model

Lalita N Nongkay (Thai Nichi Institute of Technology, Thailand), Thongchai Kaewkiriya (Thai-Nichi Institute of Technology, Thailand) 587

Factors Influencing the Thai Elderly Intention to Use Social Network for Quality of Life A Case Study LINE Application

Mananya Narkwilai (King Mongkut's University of Technology Thonburi, Thailand), Suree Funilkul (KMUTT, Thailand), Umaporn Supasitthimethee (KMUTT, Thailand) 
Reserch and Development of the City Commuter Installed ICT Functions in Consideration of Usability

Kohei Okumura (National Institute of Technology, Kitakyushu College, Japan), Shigeru Kuchii (National Institute of Technology, Japan), Sumet Prabhavat

(King Mongkut's Institute of Technology Ladkrabang, Thailand) 599

An Integrated Model of Business Intelligence Adoption in Thailand Logistics

Service Firms

Singha Chaveesuk (King Mongkut's Institute of Technology Ladkrabang, Thailand)

Cloud Computing Implementation Explained: A Tale of Two SMES

Nattakarn Phaphoom (Panyapiwat Institute of Management, Thailand), Xiaofeng Wang (Free University of Bolzano, Italy), Pekka Abrahamsson (Free University of Bolzano, Italy) 609

\section{Software Engineering, Services, and Information Technology}

On the Reliability of Diversity and Redundancy-Based Search Metrics

Ake Tangsomboon (King Mongkut's Institute of Technology Ladkrabang, Thailand), Teerapong Leelanupab (King Mongkut's Institute of Technology Ladkrabang, Thailand)

Improvements the HANN-L2F for Classification by Using K-Mean

Narissara Eiamkanitchat (Department of Computer Engineering, Faculty of Engineering, Chiang Mai University, Chiang Mai, Thai, Thailand), Jirawat Teyakome (Center of Excellence in Digital Socio-Economy Social Research Institute, Chiang Mai University, Thailand)

Tropical Cyclone Track and Intensity Forecasting Using Remotely-Sensed Images

Arthit Buranasing (King Mongkut's University of Technology North Bangkok, Thailand), Akara Prayote (King Mongkut's University of Technology North Bangkok, Thailand)

A Cell-MST-Based Method for Big Dataset Clustering on Limited Memory Computers

Duong Van Hieu (King Mongkut's University of Technology North Bangkok, Thailand), Phayung Meesad (King Mongkut's University of Technology North Bangkok, Thailand)

Automated English Mnemonic Keyword Suggestion for Learning Japanese Vocabulary

Orapin Anonthanasap (King Mongkut's Institute of Technology Ladkrabang, Thailand), Monticha Ketna (King Mongkut's Institute of Technology Ladkrabang, Thailand), Teerapong Leelanupab (King Mongkut's Institute of Technology Ladkrabang, Thailand) 